\title{
Educação e Ambiente, entremeios para imagens do humano ${ }^{1}$
}

\author{
Antonio Carlos Amorim² \\ Unicamp - Faculdade de Educação \\ Pesquisador CNPq - Bolsista Produtividade 2
}

resumo: Realizo neste artigo um trabalho com imagens que está fortemente associado às ponderações a respeito do esgotamento de efeitos da categoria representação, com o intuito de reterritorializar a compreensão de realidade pelas linhas da atualização do virtual, que se apresenta como potente no esboço de um plano de pensamento com imagens para a percepção do bumano em publicações de divulgação científica do Programa de Pesquisas em Caracterização, Conservação e Uso Sustentável da Biodiversidade do Estado de São Paulo (BIOTA-FAPESP), foco de minha presente pesquisa.

palavras-chave: Imagem, Realidade, Humano, Educação.

abstract: In this paper, I make a work with images which is strongly connected with the considerations about the breakdown of effects of the representation category. The idea is to reterritorialize the understanding of reality through the lines of virtual world actualization, which is a powerful process for outlining the plane of thought with images for the perception of the buman element in science publications of the Research Program on Characterization, Conservation and Sustainable Use of the Biodiversity of the São Paulo State (BIOTA-FAPESP), focus of my present research.

keywords: Image, Reality, Human, Education.

1 Texto referente à pesquisa Educação, Ciências e Cultura: território em fronteiras no Programa BIOTA--FAPESP (Processo FAPESP n. 2006/00752-9). Uma versão deste artigo foi apresentada na Mesa Redonda "Práticas de Pesquisa em Educação e Educação Ambiental: o debate modernidade e pós-modernidade" durante o IV Encontro de Pesquisa em Educação Ambiental, ocorrido em Rio Claro de 15 a 18 de julho de 2007.

2 E-mail: acamorim@unicamp.br 


\section{Avessos}

A publicação Olhar amplo sobre a biodiversidade foi lançada em 2006 e tem como principal objetivo divulgar a partir de textos e imagens alguns resultados de projetos sobre biodiversidade financiados pela FAPESP, com destaque para o Programa de Pesquisas em Caracterização, Conservação e Uso Sustentável da Biodiversidade do Estado de São Paulo (BIOTA-FAPESP).

Em dezembro de 2004, na Revista Pesquisa FAPESP n. 44, foi publicada a reportagem Natureza sob novo olhar, em que se enuncia o Programa BIOTA na perspectiva da mudança dos modos de produção de conhecimento e sistematização da informação estabelecidos pela história natural, deslocando-os para o compartilhamento de dados, em uma rede virtual de trabalho com a biodiversidade, da qual a educação ambiental é um dos alicerces.

Os olhares nessas duas publicações são similares aos dos animais taxidermizados no filme documentário Un animal, des animaux (França, 1994), dirigido por Nicolas Philibert, cujo tema é a reforma da Galeria de Zoologia do Museu de História Natural de Paris, reaberta ao público em 1994. A câmera filmadora encontra em várias tomadas os olhos "postiços" dos animais taxidermizados que "assistem" à reforma das galerias do museu, à espreita de sua ressurreição em outro contexto, talvez diferente da história natural que narravam antes de 1991. Olhares atentos, ansiosos, com expectativas, assombrados com a demolição de paredes, vitrines e tetos. Como é comum em filmes documentários, as relações entre olhos, câmera e espectador estão em continuidade sensório-motora e de identificação. São, portanto, os olhos das pessoas que assistirão a esse filme que conduzem, interrompem e subtraem a narrativa cinematográfica ${ }^{3}$.

\footnotetext{
3 Em outro documentário, La Ville Louvre (França, 1990), também sobre museus e do mesmo diretor, as pinturas e esculturas são os olhos enquadrados, sujeitos da espera pelo espaço reformado. Em Être et avoir (França, 2002; no Brasil, Ser e Ter), outro documentário do mesmo diretor, são alunos, professor e objetos escolares que ganham a intensidade tanto dos olhares quanto da reforma estrutural.
} 


\section{Conjunto de Imagens 1}
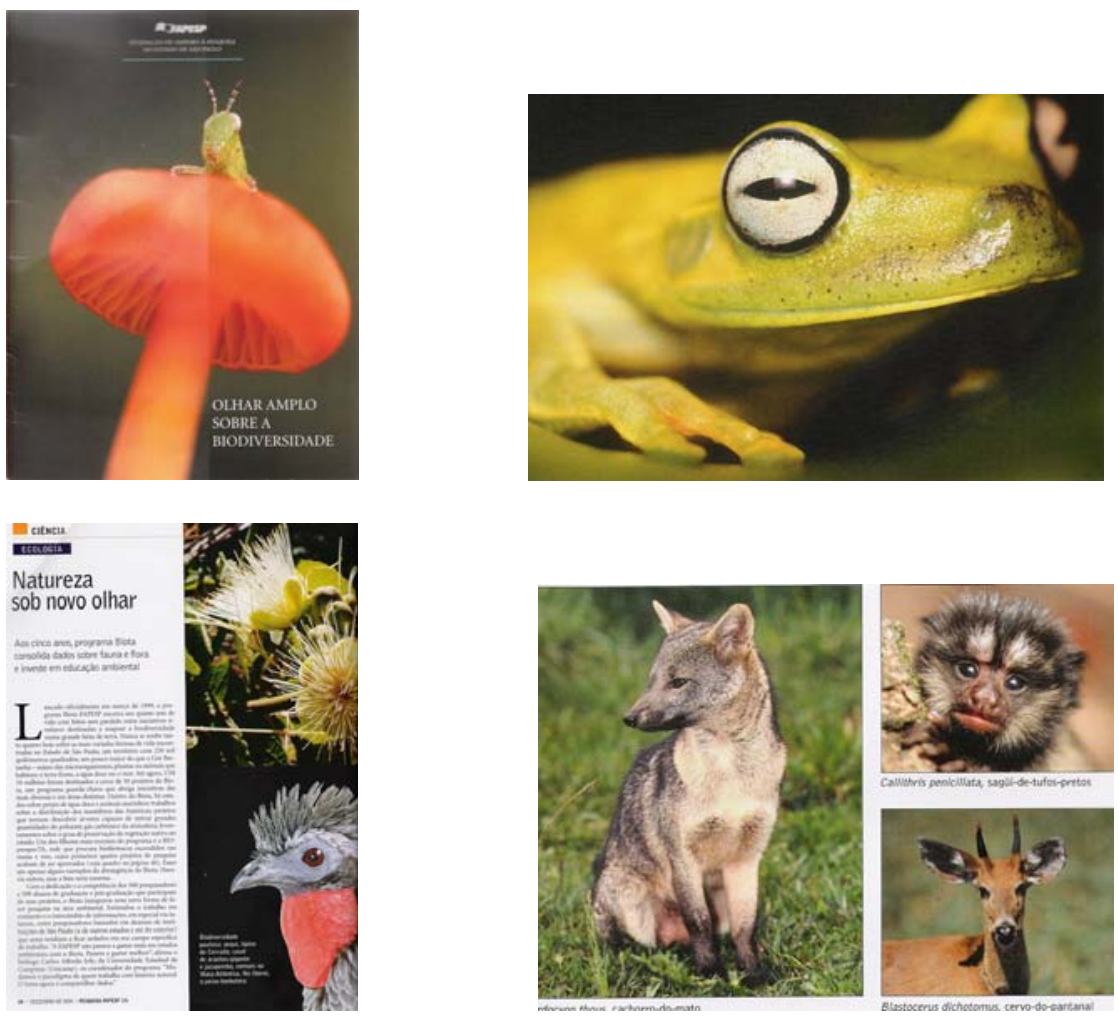

O que deseja a continuidade de efetuação desse estilo de pensamento com a representação?

Nas pesquisas que desenvolvo ou oriento 4 sobre o Programa de Pesquisas em Caracterização, Conservação e Uso Sustentável da Biodiversidade do Estado de São Paulo (BIOTA-FAPESP), uma das pulsantes questões refere-se ao fato de que as discussões a respeito de

${ }^{4}$ Projetos de Doutorado: Composições e Adensamentos: história natural, educaşão, biologia, de Érica Speglich (financiamento da CAPES/CNPq), e Bios e Borgues: filosofia, ciência e arte movimentando a educação, de Alda Romanguera. Projetos de Iniciação Científica: Natureza e Cultura em Práticas de Educação Ambiental: o caso do Bosque dos Jequitibás, Campinas, SP, de Eugênia Carolina Barioni (PIBIC/CNPq); Reportagens sobre o Programa Biota/Fapesp e suas potencialidades para o ensino de Biologia, de Marcelo Ananias, e Alberto Baraya e o berbário de flores de plástico, outras fronteiras entre natureza e cultura, de Valdemir Silva. Os três projetos de IC são criações da disciplina de graduação "Iniciação Científica em Ensino de Biologia". 
biodiversidade ganham um especial destaque quando dimensionadas em seus aspectos éticos e constituidores de representações de natureza, de seres humanos e de "relações sustentáveis". Os conhecimentos científicos, em suas finalidades educativas, associam-se a valores que querem, na organização das ações educativas, modificar e produzir um cidadão/sujeito consciente. É exatamente nesse território da produção de identidades e diferenças do/para/com o bumano como similarmente fiz em Amorim (2006), quando se está discursando sobre biodiversidade, que esboçarei algumas linhas de pensamento.

É possível considerar tais olhares como enunciados, pois representam a emissão de singularidades, de pontos singulares num espaço correspondente. As formações e transformações desses mesmos espaços são importantes menos por seu caráter de novidade, originalidade ou de reprodução, repetição. "O que conta é a regularidade do enunciado: não uma média, mas uma curva. $\mathrm{O}$ enunciado, com efeito, não se confunde com a emissão de singularidades que ele supõe, mas com o comportamento da curva que passa na vizinhança delas, e mais geralmente com as regras do campo em que elas se distribuem e se reproduzem. É isso que é uma regularidade enunciativa" (DELEUZE, 2005, p. 16, grifo do autor).

A regularidade enunciativa olhares no museu, em publicação especial da FAPESP e em artigo de divulgação científica, posiciona os animais e as plantas como sujeito na terceira pessoa ou como função derivada. Por isso, sua ação enunciativa não é a de uma primeira pessoa que inicia o discurso, mas o discurso está iniciado no invisível que o olhar vê, mas não é mostrado na imagem. Os olhares enunciativos "não são palavras, frases ou proposições, mas são formações que fazem com que os seres da natureza movimentem uma estrutura discursiva, apenas quando mudam de natureza, tomando o lugar do diz-se, distribuindo-se, dispersando-se em espessura na linguagem" (DELEUZE, 2005, p. 29). Isso ocorre quando alcançam o bumano, enunciado em multiplicidades e não uma estrutura ou um sistema. O olhar enunciativo é conector sensório-motor para a entrada do homem nos discursos da biodiversidade pelas imagens.

É interessante observar, como assinala Santos (2003) a partir de considerações sobre a Modernidade e os escritos de Walter Benjamin, que as técnicas fotográfica e cinematográfica prometem expor à percepção do homem moderno a realidade última, em suas dimensões tanto psíquica 
quanto física, graças à desconstrução das aparências e ao acesso controlado a um mundo reconstruído por uma perspectiva objetiva, enquanto dado. "Neste sentido, a técnica da fotografia e do cinema é instrumento de conhecimento, isto é, de poder, e como tal deve ser utilizada politicamente" (SANTOS, 2003, p. 158).

A modernidade que se instaura nessa regularidade das imagens (enunciados) e sua objetividade não gera a equivalência olhar da câmera = olhos da natureza. As diferenças produzidas pelos aparatos fotográfico e cinematográfico permitem encontrar o bumano em uma invisibilidade discursiva. Ou seja, a realidade é conhecida pelo/no deslocamento inconsciente que o olhar da câmera faz querer.

Ainda sob as linhas argumentativas de Santos (2003), a passagem da percepção do homem moderno ${ }^{5}$ à fruição estética pós-moderna da experiência perceptiva niilista ou a visão disléxica, expressão de Virilio, indica a impossibilidade de representar. "O essencial do que vejo não está mais, por definição, a meu alcance e, ainda que se encontre ao alcance do meu olhar, já não se inscreve obrigatoriamente no mapa do 'eu posso' " (SANTOS, 2003, p. 173).

O que existe é a erosão da realidade. "Amnésia topográfica e teletopologia, teléscopage, dislexia visual e incapacidade de representar, transferência do olhar e inconsciência, desregulação da percepção e perda da fé perceptiva - no fio do texto Virilio vai desenhando não uma metamorfose, mas uma crise que vai abrir as portas para a modelização da visão e a estandardização do olhar" (SANTOS, 2003, p. 174).

O que existe é que se continua, nos tempos pós-modernos, efetuando o estilo de pensamento representacional. Persistente desejo de quê??

5 “[...] longe de uma concepção segundo a qual a câmera nos abre, pela primeira vez, a experiência do inconsciente óptico; longe de uma técnica fotográfica e cinematográfica capaz de expor a realidade última" (SANTOS, 2003, p. 169). 


\section{Poética e Imagética Moderna - Pós-Moderna}

Os esquemas de poder ${ }^{6}$, os diagramas ${ }^{7}$ de força engendram também dobras subjetivas que transformam as forças do "exterior" em forças do interior capazes de reabrir as rachaduras do Ser e de determiná-lo mediante novos esquemas de Pensamento. Se o Pensamento é possível enquanto ato livre, é porque o Ser é rachado e divergente. Se o Pensamento pode determinar a Idéia-Ser em novas configurações conceituais, é porque o Pensamento é apenas uma dobra do Ser, e porque o Pensamento e o Ser são constituídos da mesma substância: a força. (GUALANDI, 2003, p. 124).

Ao deportar o pensamento de Deleuze, Gualandi pergunta se a filosofia “anti-humanista" do filósofo francês libertou-se, mesmo, de fato e de direito, da questão do homem. Em seu livro sobre Deleuze, Gualandi (2003) chama a atenção para dois constituintes da linguagem deleuzeana as metáforas da mão e do olho - e para a relação do campo de força com o plano da intuição, a fim de compreender a presença constante do homem na linguagem: "O diagrama nunca é efeito ótico, mas potência manual desencadeada. É uma zona frenética onde a mão não é mais guiada pelo olho que se impõe à vista como uma outra vontade, que se apresenta tanto como acaso, acidente, automatismo, involuntária” (DELEUZE, 2005).

Mão e olho, embora reafirmem o homem, para Deleuze são linhas de fuga, potências afirmativas do sujeito humano sem consciência ou não passível de reação em uma sociedade da mídia na qual há proliferação de imagens. Com essa condição diagramática do homem, me é possível pensar que novos discursos sobre emancipação se fundam na oscilação, pluralidade e, sobretudo, erosão de realidade. São descentrados dos

6 A teoria pós-moderna talvez seja inevitavelmente contraditória: os impulsos antitotalizantes e antiessencializantes de Foucault parecem conduzir ao paradoxo da essencialização transistórica do não essencializável - o poder -, uma vez que o homem está dissolvido nas estrias da própria linguagem, transformado em pouco mais que sujeito constituído, pronome falante do discurso.

7 “O que é um diagrama? É a exposição das relações de forças que constituem o poder. O diagrama, ou a máquina abstrata, é o mapa das relações de forças, mapa de densidade, de intensidade, que procede por ligações primárias não localizáveis e que passa a todo instante por todos os pontos, ou melhor, em toda relação de um ponto a outro" (DELEUZE, 2005, p. 46). 
modelos sobre autoconsciência plena do homem, consistindo agora num deslocamento e numa liberação das diferenças, aproximando-se das análises que Santos (2003) faz em seu texto ao discutir a eleição da experiência estética como expressão do movimento de emancipação do homem pós-moderno.

Não me seria possível abordar, neste artigo, a relação entre modernidade e pós-modernidade a não ser pelo caminho do meio, da passagem, das suas entrefetuações. E que não são poucas, qualitativamente e em sua complexidade. $\mathrm{O}$ debate entre modernidade e pós-modernidade que interessaria às práticas de pesquisa em Educação e Educação Ambiental tem ramificações extensas e emaranhadas. Escolhi uma linha, pouco provável de me arremessar em um jogo de gradientes de intensidade, qualidades e comparações, atitudes das quais fujo, buscando encontrá-las às avessas. A ausência do homem (sujeito), quer por seu fim, sua morte ou seu desaparecimento, é política de continuidade modernidade - pós-modernidade. Ele não veio, ele vira? A estrutura (o mundo, a Idéia, as coisas) está à sua espera para acontecer.

Pelo reiterado agenciamento dos olhares, a passagem Modernidade - Pós Modernidade é intensidade na sombra do humano, em seu estado de sono, sonambulismo e histeria, em sua esquizofrenia, virtualização e tecnicização, nas transformações entre corpo orgânico - sem órgãos mercadoria - biopolítica - sensação etérea.

Relações de poder ou campo de força são expressões que afirmam o homem, sua existência. Com essa lembrança potente, revivemos no sempre retorno a questões fundamentais, essenciais, representacionais. O fim da história, o fim do homem. Nesse contexto, também nomeado de pósmodernidade, e por muitos considerado niilista, tem-se configurado como discurso politicamente interessado o que reafirma as categorias da representação e sua eficácia interpretativa nas discussões sobre a realidade e a ficção.

Um dos efeitos do pensamento representacional é derivar lembranças pulsantes, transformadas em nosso desejo desenfreado pelas memórias, por aquilo que perdemos e que tem que ser resgatado, reatado, colocado em camadas da cultura, conservado. Os variados discursos 
ambientalistas, com suas tônicas na sustentabilidade, biodiversidade, bioprospecção, são intensidades que circunscrevem o sentimento de perda, de ausência e de esquecimento que efetua o excesso de tempo "presente" da pós-modernidade.

De acordo com Rancière (2000), representar (uma alternativa para a Poética), com efeito, significa duas coisas. Primeiramente, a obra é imitação de uma ação. Por meio de sua semelhança, ela faz reconhecer algo que existe fora dela. Em segundo lugar, a obra é a ação de representar. Ela é encadeamento ou sistema de ações, agenciamento de partes que se ordenam segundo um modelo bem definido: o agenciamento funcional de um organismo. A obra é viva por ser um organismo. Isso quer dizer que a techne da obra existe à imagem da natureza, da potência que encontra no organismo vivo em geral, e no organismo humano em particular, sua efetuação.

Para fugir da representação, teríamos que apostar no fim do pensamento do bumano como corporeidade orgânica.

Colocar em movimento essas idéias constitui, para mim, interessante caminhar no campo da Educação para inventar alternativas ao pensamento representacional. As leituras transversais das obras de Gilles Deleuze sobre imagens e literatura permitem que nos desloquemos de um plano da representação para a paisagem da sensação. Em que essa efetuação potencializaria pensar Educação Ambiental?

Ter uma sensação é, ao mesmo tempo, representá-la, mas isso determina um duplo movimento, pelo qual, de um lado, fazemos de toda sensação uma magnitude extensiva e, por outro lado, não deixamos de sentir, sem poder representá-lo, aquilo que possibilita a extensão como tal. Ao representarmos uma intensidade, ela desaparece, ou melhor dizendo, torna-se extensão, passando a ser explicada de acordo com uma quantificação. Por esse motivo, esclarece Deleuze, a diferença, para se manter como pura intensidade, implica-se na sensação; a diferença está implicada no sistema do sensível, mas anula-se ou desaparece quando é explicada. A diferença é inobjetivável e irrepresentável; ela não é nem diversidade da percep̧̧ão nem identidade do conceito, mas um diferencial intenso que atravessa e gera tanto um como o outro. É como se a superfície do extenso recobrisse uma profundidade intensa (CRAIA, 2005, p. 75-76). 
Pensar a educação ambiental pela relação entre superfícies do acontecimento e diferença é indicar suas potências como devir que liberaria a diferença e não a subordinaria ao fundamento metafísico ou à essência. É compor desconstruções da representação como potência propulsora em contextos de pesquisa contemporânea. Mais especificamente, chegar ao limite das relações entre identidades e diferenças e alcançar o instante em que uma é quase a outra, instante da mudança de natureza, ou seja, o acontecimento.

$\mathrm{O}$ acontecimento subsiste à linguagem e ocorre no mundo, nos objetos. Toda linguagem envolve coisas incorpóreas, ou seja, o acontecimento puro. Age no mundo, intervém nele, não é informação nem comunicação. O senso de proposição é o acontecimento na linguagem; portanto, não é enunciação, ação do sujeito que aparece e irrompe a narrativa. Não são, então, apenas os avessos, seção de abertura deste artigo.

A relação entre acontecimento e corpo está na encarnação e distribuição de sentidos nos corpos, extensão da linguagem-realidadesensação.

\section{Sentidos, inorganicidade corpórea}

Dimitri Kirsanoff, no seu filme Brumes d'automne (1928), criou um clima poético em torno da atriz, e sua esposa, Nadia Sibirskaya, usando duplas exposições e reflexões de imagens que dessem uma idéia de dissolução, em um estilo de olhar para a frente, de uma maneira subjetiva, similar à do cinema-olho, uma nova concepção de montagem que conecta qualquer ponto do universo a outro, em qualquer ordem temporal. A experimentação está na crítica à ilusão do olho e todo conhecimento fisiológico e orgânico do corpo humano articulado à percepção e à sensibilidade: “O 'cine olho' [sic] implica o ultrapassamento [sic] do olho humano rumo a um olho não-humano, que estaria nas coisas" (PARENTE, 2000, p. 94). O cinema-olho ultrapassa o intervalo de movimento. É importante lembrar que ele é uma das marcas de passagem entre o cinema clássico e o moderno; numa intensificada experimentação de movimento e tempo com as imagens. Para tanto, é importante a idéia de uma livre navegação das superfícies planas da imagem, que define, no cinema 
experimental, a construção de um estado gasoso da percepção. As velocidades a serem atingidas nesse tipo de cinema não estão nos personagens, que em geral são pouco ativos; o que há são superfícies loucas de cor, vibrações e oscilações. Segundo Parente (2000) - com base nos estudos de Gilles Deleuze -, trata-se de um mundo anterior ao começo, antes de haver palavra. Um mundo cézanniano de antes dos homens.

É o enigma (freqüentemente comentado) de Cézanne: 'o homem ausente, mas inteiro na paisagem'. Os personagens não podem existir, e o autor só pode criálos porque eles não percebem, mas entram na paisagem e fazem eles mesmos parte do composto de sensações. É Ahab que tem as percepções do mar, mas só as tem porque entrou numa relação com Moby Dick que o faz tornar-se baleia, e forma um composto de sensações que não precisa de mais ninguém: Oceano. (DELEUZE; GUATTARI, 2002, p. 219-220).

O filme é quase um poema que Kirsanoff dedicou à face de Nadia Sibirskaya, e as imagens de natureza, em especial de árvores, são tomadas de filmagem envoltas em lágrimas de uma mulher que recorda seu passado, queimando cartas velhas. A tela mostra suas memórias. Imagens que se repetem insistentemente em narrativas amorosas que se transformaram em clichês da indústria audiovisual de massa. Do lado de fora da casa (ou de suas memórias), está chovendo, as gotas de água das árvores e a paisagem de outono, inverno, em que a experimentação de luz e sombras é intensa. As lembranças expressam-se nas imagens distorcidas, resultantes da experimentação visual, refletidas nas poças d'água. O filme é uma seqüência de planos similar à edição de fotografias, várias delas de elementos da natureza. Esse filme não significa representar, mas criar a sensação na memória, na tela do cinema.

Karin Santos coletou amostras de 6.500 árvores. Em cada um dos 11 fragmentos de mata, adotou como método reunir 500 indivíduos em todos os estágios de crescimento e, invariavelmente, detectou 100 espécies diferentes por grupo. Para avaliar a saúde da vegetação, a pesquisadora fotografou as copas das árvores de baixo para cima, utilizando uma lente grande angular que resultou em fotos hemisféricas, imagens do "dossel". 


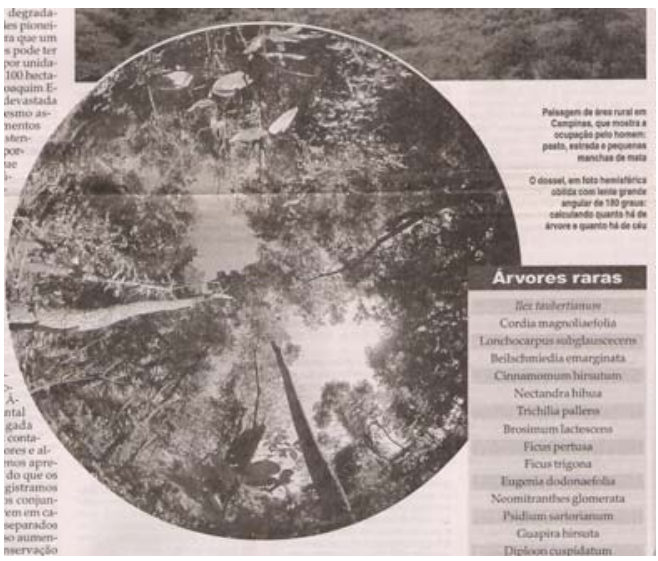

Este termo técnico, embora grafado com dois "s", permite medir quanto há de árvore e quanto há de céu numa mata. "A imagem é contrastada e um programa de computador calcula os percentuais de preto e de branco. O preto é entendido como dossel e o branco, como céu: quanto mais dossel no hemisfério total da foto, mais bem preservado está aquele ponto da mata", explica Sugimoto (2003, p. 9).

Fechando drasticamente o diafragma, ou acelerando a velocidade de sua câmera, pouco importa, Vicente impôs uma circunspeção, uma disciplina

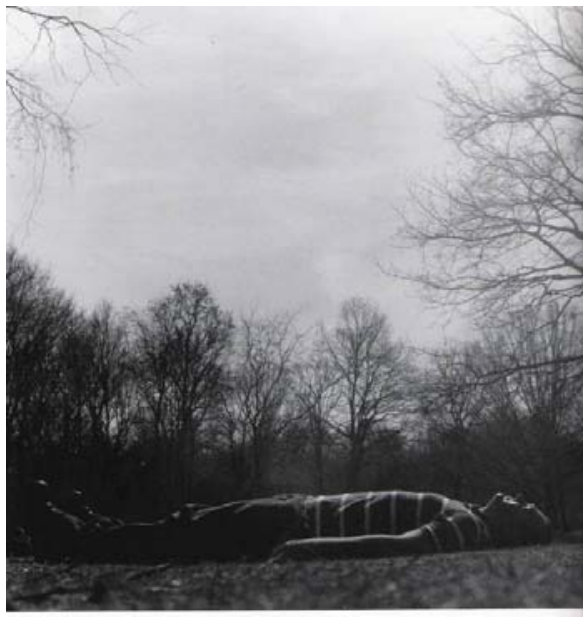
à luz destas suas fotografias, que não se explica somente como mera aventura de estilo. Suas sombras, silhuetas e penumbras, ao invés de espaços fotometricamente contemplativos, querem mostrar espacialidades imaginativas, abertas aos mistérios da interação emocional com becos e claustros. Nestas fotografias, há sempre uma reticência (BARRETO, 2006, p. 147).

Vicente de Mello. Chris Gulliver, 2005.

Embora essas três imagens mudem de finalidade e tenham diferenças de grau entre si, por isso a relação entre uno e multiplicidade é nelas imanente; as diferenças de natureza dessas imagens poderiam ser consideradas um decalque temporal, uma persistência de memória nos/pelos/com elementos do ambiente com os quais o/nos percebemos? Em outras palavras, a sua natureza é representacional? 
Aposto que, entre essas três imagens,

a questão não é a da organização, mas da composição; não do desenvolvimento ou da diferenciação, mas do movimento e do repouso, da velocidade e da lentidão. A questão é a dos elementos e das partículas que chegarão ou não rápido o bastante para operar uma passagem, um devir ou um salto sobre um mesmo plano de imanência pura. E se, com efeito, há saltos, fracassos entre agenciamentos, não é em virtude de sua irredutibilidade de natureza, mas porque há sempre elementos que não chegam a tempo, ou que chegam quando tudo acabou, tanto que é preciso passar por neblinas, ou vazios, avanços e atrasos que fazem parte eles próprios do plano de imanência. (DELEUZE; GUATTARI, 2002, p. 41).

As oposições entre luz e sombra, preto e branco, em foco e fora de foco, movimento e reação podem indicar os desejos de lembrança, de memória psicológica ou narrativa dessas imagens, em sua produção para representar algo a alguém.

Se isso é verdadeiro, também o é que a desconexão potente entre essas imagens acontece nos seus desdobramentos para além de uma linha de tempo, em "um fluxo de memória, com múltiplas coexistências virtuais, que apresentam a um determinado corpo nada mais que imagens" (VASCONCELLOS, 2006, p. 22), com uma consciência que não é mais fonte produtora de imagens, mas uma espécie de tela negra ou opaca, passível de as imagens aparecerem.

Os estudos de Gilles Deleuze sobre imagem têm nas obras de Bergson um encontro proliferante: a imagem foge de sua representação mental, psicológica, e ganha força e status ontológico.

Com Deleuze, leitor de Bergson, a consciência sai do campo da representação (das imagens) para o campo da apresentação (das imagens). E isto somente é possível se procurarmos entender o impacto da noção de virtualidade em Bergson. A virtualidade da memória, ou seja, o salto do passado que se contrai e se distende para o presente leva-nos a compreender a dimensão propriamente ontológica do homem e por que não dizer: somos homens porque lembramos. Mas não simplesmente 
lembramos. Somos a possibilidade ativa da construção de afetos que, para se atualizarem, fazem, necessariamente, o caminho das lembranças. Somos imagens de lembranças e lembranças de imagens. Somos o próprio fluxo do devir (VASCONCELLOS, 2006, p. 23 -24).

As três imagens, persistentes contrastes de luz, experimentação fotográfica e cinematográfica com árvores, atualizam o fluxo de virtualidades temporais e adensam a duração do presente e do humano como ser em devir. Essas imagens, como fusão tempo-ser-devir, são os afetos e os perceptos não orgânicos, humanos imperceptíveis, fora da lógica da representação. Incidem no acontecimento (Quão rápido ele é? É possível perdê-lo? É muito rápido ou muito lento para ser percebido?) e diagramam-se numa desterritorialização do tempo.

Para mim, essas seriam possíveis imagens do pensamento que Deleuze (2006) lança nas três páginas do ensaio Response to a question on the subject, pois operam na individuação ao contrário, na liberação de singularidades do que podemos ser antes de sermos pessoas, movendo-nos em ações imperceptíveis.

Esquecimento e vazios, duas condições importantes para existir na pós-modernidade.

\section{Referências}

AMORIM, Antonio Carlos Rodrigues de. Nos limiares de pensar o mundo como representação. Pro-posições, Campinas, v. 17, n. 1, p. 177-194, jan./abr. 2006.

BARRETO, Waldir. Atrás do olhar. In: MELLO, Vicente. Áspera Imagem. Rio de Janeiro: Instituto Telemar, 2006. p. 147-149

CRAIA, Eladio C. P. Deleuze e a ontologia: o ser e a diferença. In: ORLANDI, Luiz B. L. (Org.). A diferença. Campinas: Editora da Unicamp, 2005. p. 55-90.

DELEUZE, Gilles. Foucault. Trad. de Claudia Sant'Anna Martins. São Paulo: Brasiliense, 2005.

Two Regimes of Madness. Texts and interviews 1975-1995. Translated by Ames Hodges and Mike Taormina. London: MITPress, 2006. p. 349-351.

DELEUZE, Gilles; GUATTARI, Félix. Mil Platôs, Capitalismo e Esquizofrenia. Trad. de Suely Rolnik. São Paulo: Editora 34, 2002. v. 4. $1^{\text {a }}$ Reimpressão. 
GUALANDI, Alberto. Deleuze. Trad. de Danielle Ortiz Blanchard. São Paulo: Estação Liberdade, 2003. (Figuras do Saber).

PARENTE, André. Narrativa e modernidade. Os cinemas não-narrativos do pós-guerra. Campinas, SP: Papirus, 2000.

RANCIÈRE, Jacques. Existe uma estética deleuzeana? In: ALLIEZ, Eric (Org.). Gilles Deleure, uma vida filosófica. Coordenação e tradução de Ana Lúcia de Oliveira. São Paulo: Editora 34, 2000. p. 505-516.

SANTOS, Laymer Garcia dos. Modernidade, pós-modernidade e metamorfose da percepção. In: _. Politizar as novas tecnologias. O impacto sócio-técnico da informação digital e genética. São Paulo: Editora 34, 2003. p. 153-182.

SUGIMOTO, Luiz. Pesquisadora localiza árvores raras em São Paulo. Jornal da Unicamp, Campinas, 1-7 dez. 2003, p. 9.

VASCONCELLOS, Jorge. Deleuze e o cinema. Rio de Janeiro: Editora Ciência Moderna, 2006.

Artigo recebido em 06/11/2007 - Aprovado em 28/05/2008 